\title{
Terminalidade da vida: questões éticas e religiosas sobre a ortotanásia
}

\section{End of life: ethical and religious issues about orthotanasia}

\author{
Marcelo S. Xavier'; Carmen Silvia Molleis Galego Miziara²; Ivan Dieb Miziara ${ }^{3}$
}

\begin{abstract}
Xavier MS; Miziara CSMG; Miziara ID. Terminalidade da vida: questões éticas e religiosas sobre a ortotanásia. Saúde, Ética \& Justiça. 2014;19(1);26-34.

RESUMO: A ortotanásia tem sido amplamente discutida nos últimos anos, principalmente após a publicação da Resolução CFM n $^{\circ}$ 1805/2006 e, posteriormente, com a publicação do novo Código de Ética Médica. O objetivo deste estudo é abordar e identificar as questões éticas e religiosas que exercem influência sobre o tema e que devem ser consideradas diante de pacientes em fases terminais da vida. Para atingir esse objetivo foi realizada revisão de literatura nas principais bases de dados de livre acesso, em textos publicados e em entrevistas de posicionamentos de líderes religiosos nos veículos de comunicação. A maioria das religiões aceita a morte como processo natural, sendo a ortotanásia vista de forma natural. Conclui-se que a religião não interfere negativamente em relação à ortotanásia.
\end{abstract}

DESCRITORES: Cuidados Paliativos na Terminalidade da Vida; Cuidados Paliativos; Religião.

1. Hospital A.C.Camargo.

2. Departamento de Medicina Legal, Ética Médica e Medicina Social e do Trabalho da Faculdade de Medicina da Universidade de São Paulo

3. Departamento de Medicina Legal, Ética Médica e Medicina Social e do Trabalho da Faculdade de Medicina da Universidade de São Paulo

Endereço para correspondência: Marcelo S. Xavier - Rua Professor Antônio Prudente, 211, Liberdade, São Paulo-SP, CEP 01509-010.msxmed@yahoo.com.br 


\section{INTRODUÇ̃̃̃O}

A medicina tem a função de curar às vezes, aliviar muito frequentemente e confortar sempre, como referiu Oliver Holme ${ }^{1}$. Porém, a cura ganhou grandes proporções com o advento de novas tecnologias, norteando as condutas. Com objetivo direcionado à cura, muitas vezes o paciente é visto como uma doença a ser tratada, e não de forma completa. A morte não é mais uma possibilidade e, assim, o ser humano é deixado de lado, como diz Marie de Henezel ${ }^{2}$. É necessário que os profissionais aceitem o processo de morrer dos pacientes considerando-o não como falha médica, mas, sim, como sequência natural da $v^{2} d^{2-5}$, devendo a tecnologia participar protegendo o indivíduo e não ocasionando risco ao mesmo ${ }^{5,6}$.

Porém, há uma tendência à revalorização do paciente, com maior humanização. $\mathrm{O}$ paciente, aquele que espera, passou a ser visto como cliente, e a participar das decisões referentes ao seu tratamento. Ao participar do próprio tratamento, o cliente faz jus ao conceito de autonomia da bioética, assumindo seus direitos e deveres ${ }^{6-10}$

O paciente terminal, que é o doente crônico em situação grave e irreversível, em que se prevê a morte como próxima e para quem a medicina não oferece nenhuma chance de cura, é alvo constante de discussões bioéticas ${ }^{11}$. Discute-se a fase da terminalidade, na qual deve ser valorizada a qualidade da vida, e também a condição da morte, oferecendo dignidade ao indivíduo ${ }^{3,12,13}$. A crença em um processo de morrer doloroso, com dependência, sofrimento, gera grande receio da morte. No entanto a morte, ou o processo de morrer, pode transcorrer de forma amena para os pacientes e seus familiares, devendose, dessa forma, mudar o conceito arraigado na nossa cultura ${ }^{4,6,14}$. Há necessidade de diminuir o sofrimento do paciente e de seus familiares e, considerando que $40 \%$ dos leitos estão ocupados com pacientes terminais nos Estados Unidos da América (EUA), é de extrema importância que temas relativos à terminalidade, ao processo de morrer $\mathrm{e}$ também aos cuidados paliativos sejam não só discutidos, mas melhorem a prática médica diária ${ }^{8,10,15-17}$. Como base desta discussão há a ortotanásia, conduta já aceita pela justiça e pela comunidade médica, e que levanta as mais diversas discussões no seu entorno ${ }^{13,18}$.

Sabe-se que o paciente e os profissionais de saúde sofrem influências culturais, regionais, religiosas e morais sobre suas decisões. Visa-se, dessa forma, a avaliar os conceitos vigentes e suas influências na sociedade atual. Este estudo não visa posicionar-se em relação à ortotanásia, mas, sim, defender um tratamento digno aos doentes, respeitando o processo do morrer e fornecendo um tratamento humano. A morte, apesar de não ser uma condição indigna, pode ser acompanhada de um tratamento indigno recebido pelo doente no final da vida $^{1,2,19}$. O objetivo deve ser a dignidade do doente, tratálo como pessoa e não salvar a vida a qualquer custo 9 .

\section{OBJETIVOS}

Expor questões éticas e religiosas envolvendo a terminalidade da vida e mostrar o entendimento de diversas religiões sobre ortotanásia, através de revisão de literatura.

\section{MÉTODO}

Estudo descritivo, analítico e qualitativo, através de revisão de literatura. Foi realizada pesquisa nas principais bases de dados de livre acesso dos últimos 10 anos. Alguns artigos de importância para a pesquisa foram incluídos apesar de ultrapassar o limite dos 10 anos. Os descritores utilizados foram: cuidados paliativos, terminalidade da vida e religião. Foram incluídos artigos em língua espanhola, inglesa e portuguesa. Foi realizada pesquisa em sites de busca para publicações livres com opiniões de líderes religiosos sobre morte, ortotanásia e eutanásia.

\section{REVISÃO DE LITERATURA E DISCUSSÃO}

\section{Conceito de vida}

O termo vida é de difícil conceituação. Mesmo a biologia, ciência que estuda a vida, não consegue definir com exatidão o que é vida. Vários filósofos já tentaram conceituar vida. Aristóteles conceituou vida como "aquilo pelo qual um ser se nutre, cresce e perece por si mes$\mathrm{mo}^{(1) " 20}$. A tradição cristã conceituava a vida como aquilo que nos salva da morte e da aniquilação, conceito que permaneceu durante a Idade Média. O conceito deve ser geral, abranger todas as formas possíveis de vida, ser claro, bem definido, incluir todos os conceitos de vida que a vida moderna já possuiu e ser suficientemente especifico para diferenciar sistemas vivos de sistemas que são obviamente não vivos ${ }^{6,20}$

Atualmente, há diversas avaliações do que seria vida que convivem harmoniosamente com conceitos criados pelos diversos cultos religiosos, pelas sociedades cientificas e pelos filósofos. Porém, ainda persiste a ausência de um conceito único que satisfaça a todos os setores.

\section{Conceito de morte}

A morte existe desde o princípio do mundo,

(1) Aristotéles, Da Alma, II, 1, 412a.p.12. 
sendo um tema considerado sagrado e sobre o qual não se discutia. Ao longo dos anos muitas opiniões e conceitos foram criados, sofrendo alterações pelos aspectos filosóficos, sociais, religiosos, biológicos, legais e culturais. É um conceito dinâmico, e ainda é um tema de difícil discussão na sociedade em geral, pelo "peso" existente na palavra ${ }^{3}$.

Inicialmente na história, uma pessoa era considerada morta quando ocorria a cessação das funções cardiológica e respiratória, com o término da função do corpo e da mente. Atestava-se o óbito com métodos simples como observar a ausência de condensação em um espelho colocado em frente ao nariz, mostrando a ausência de respiração e pela ausência de batimentos cardíacos. Com a evolução tecnológica, a morte foi postergada, pois estes parâmetros puderam ser mantidos com o uso de aparelhos. Criou-se o estado de coma e o questionamento sobre a existência de vida sem consciência e sem interação com a sociedade ${ }^{1,3,21}$.

A morte passou a ser entendida como um processo de morrer e não apenas como um momento isolado. Hodiernamente, o conceito do Ministério da Saúde considera a morte encefálica como a definição legal de morte. Na morte encefálica todas as funções encefálicas são cessadas de forma irreversível. Devido a uma agressão severa, o sangue não chega ao cérebro, ocorrendo a morte de todo o encéfalo, de forma permanente e irreversível ${ }^{22,23}$. As características irreversivel e permanente são importantes, pois há situações da prática médica, como a parada total da circulação e a circulação extracorpórea, em que há paradas reversíveis ${ }^{3,7}$.

A morte ainda é pouco aceita pela sociedade, seja entre profissionais da saúde ou da sociedade leiga. Para os profissionais de saúde, é vista como falha na sua capacidade de tratamento. Entre os leigos, seja em doentes crônicos, seja em casos de morte não esperada, há incômodo, susto e preocupação ${ }^{1,3,19}$. Outro ponto envolvendo o morrer é a questão do sofrimento familiar e da exaustão do paciente. Muitas vezes, as tecnologias postergam o processo de morrer, todavia não agregam qualidade de vida. Com isso o doente tem apenas mais dias de sofrimento e a família e os amigos sofrem junto ${ }^{1,3,18,19}$.

A elaboração do enfrentamento da morte e do luto é a etapa mais difícil para o paciente e para a família, pois a assimilação da impossibilidade de cura é um momento muito doloroso e a aceitação dessa condição depende da conscientização da finitude humana ${ }^{24}$.

\section{Eutanásia, ortotanásia e distanásia}

A eutanásia é caracterizada por sempre existir a intenção de encerrar a vida. Pode ocorrer uma ação, na eutanásia ativa, ou uma omissão, na eutanásia passiva9. A eutanásia passiva ou negativa não consistiria numa ação médica, mas na omissão, isto é, na não aplicação de uma terapia médica, que ainda era indicada, com a qual se poderia prolongar a vida da pessoa enferma ${ }^{18}$.

A ortotanásia, do grego orthós (direito, normal, correto) e thánatos (morte), ou limitação médicoterapêutica, significa retirar ou não utilizar recursos terapêuticos considerados excessivos ou pouco benéficos, reduzindo a utilização de métodos que somente prolongarão o processo de morrer, não sendo possível curar o paciente ${ }^{18}$.

Quando não há opção de cura, em situação de terminalidade, deseja-se que a medicina e o direito defendam a ortotanásia. Para o direito a ortotanásia seria o momento em que não são ministrados mais medicamentos para prolongar a vida de forma artificial, quando não há cura para a enfermidade do paciente, quando os medicamentos ou terapias não trarão benefício ${ }^{18}$. O indivíduo tem direito a tratamento que lhe assegura a vida, mas não tem a obrigação de a ele se submeter. Deve ser respeitada a dignidade da pessoa, conforme norteia o artigo $5^{\circ}$, inciso III da Carta Magna de $1988^{25}$.

$\mathrm{Na}$ ortotanásia ocorre a prática de cuidados paliativos, prática multiprofissional que visa oferecer ao paciente, fora das perspectivas de cura, atendimento embasado nos aspectos físico, emocional, social $\mathrm{e}$ espiritual. Objetiva-se aliviar o sofrimento ${ }^{10,18,19,26,27}$.

Distanásia refere-se ao afastamento da morte de forma forçada, a qualquer custo. A morte torna-se uma morte difícil, prolongada além do período natural. É considerada por alguns autores como obstinação terapêutica ou crueldade terapêutica ${ }^{17,28-30}$. O conceito de obstinação terapêutica (l'acharnment thérapeutique) foi introduzido na linguagem médica pelo francês Jean-Robert Debray nos anos 50 do século XX. Nas palavras de Nunes, Amaral e Gonçalves, seu único objetivo é o de prolongar a sobrevivência, sem qualidade de vida. Contribuem para a distanásia o relativismo e o probabilismo do conhecimento médico, gerando incertezas nos profissionais $\mathrm{e}$ familiares ${ }^{17,27}$.

\section{Considerações éticas e legais}

O Conselho Federal de Medicina (CFM) publicou em 2006 a Resolução $n^{\circ}$. 1.805/2006, a qual permite ao médico "limitar ou suspender procedimentos e tratamentos que prolonguem a vida do doente em fase terminal, de enfermidade grave e incurável, respeitada a vontade da pessoa ou de seu representante legal" ${ }^{\prime 31}$. Esta parte da Resolução foi suspensa por liminar em 2007 20.26 . Em 2010, após julgamentos, a Procuradoria Federal julgou a legitimidade do CFM para legislar sobre a ortotanásia ${ }^{12}$.

Em 24 de setembro de 2009, foi publicado o novo Código de Ética Médica, a Resolução $n^{\circ}$. 193132, em vigor desde 13 de abril de 2010, que trouxe significativas inovações, principalmente em alguns artigos, onde se 
subentende a possibilidade da formalização e validade das diretivas antecipadas entre médico e paciente, conforme citado a seguir ${ }^{1,3,19,30}$ :

\section{"Capítulo I}

XXI - No processo de tomada de decisões profissionais, de acordo com seus ditames de consciência e as previsões legais, o médico aceitará as escolhas de seus pacientes, relativas aos procedimentos diagnósticos e terapêuticos por eles expressos, desde que adequadas ao caso e cientificamente reconhecidas.

XXII - Nas situações clínicas irreversíveis e terminais, o médico evitará a realização de procedimentos diagnósticos e terapêuticos desnecessários e propiciará aos pacientes sob sua atenção todos os cuidados paliativos apropriados.

Capitulo IV

É vedado ao médico

Art. 24. Deixar de garantir ao paciente o exercício do direito de decidir livremente sobre sua pessoa ou seu bem-estar, bem como exercer sua autoridade para limitálo.

Capitulo V

É vedado ao médico

'Art. 31. Desrespeitar o direito do paciente ou de seu representante legal de decidir livremente sobre a execução de práticas diagnósticas ou terapêuticas, salvo em caso de iminente risco de morte.

Art. 34. Deixar de informar ao paciente o diagnóstico, o prognóstico, os riscos e os objetivos do tratamento, salvo quando a comunicação direta possa the provocar dano, devendo, nesse caso, fazer a comunicação a seu representante legal.

Art. 41. Abreviar a vida do paciente, ainda que a pedido deste ou de seu representante legal.

Parágrafoúnico. Nos casos de doença incurável e terminal, deve o médico oferecer todos os cuidados paliativos disponíveis sem empreender ações diagnósticas ou terapêuticas inúteis ou obstinadas, levando sempre em consideração a vontade expressa do paciente ou, na sua impossibilidade, a de seu representante legal." ${ }^{32}$

Ao paciente cabe o direito de escolher entre submeter-se ou não a um tratamento. No Código de Ética Médica, o princípio da autonomia mantém o indivíduo como dono de sua própria vida, podendo limitar as invasões a sua intimidade. A inviolabilidade do direito à vida e a liberdade são também garantidos na Constituição Federal, pelo inciso XXXV, no $5^{\circ}$ artigo ${ }^{8,16,27,33}$.

\section{Espiritualidade e terminalidade da vida}

Nos últimos anos foi possível notar o aumento das questões religiosas envolvendo a terminalidade da vida, principalmente no que se refere ao tratamento paliativo. Estudo americano descreveu que 95\% dos entrevistados acreditam em alguma força superior e 93\% gostariam que seus médicos abordassem essas questões se ficassem gravemente enfermos ${ }^{34}$. A vontade espiritual do paciente deve ser considerada. Segundo Saporetti ${ }^{35}$ 77\% dos pacientes gostariam que seu médico considerasse seus valores religiosos.

A religião, segundo Freud $^{(2)}$, surgiu de uma necessidade de defesa contra as forças da natureza, como todas as outras realizações da civilização. Essa necessidade surge do desamparo que existe na infância e na idade adulta ${ }^{36}$.

\section{Aspectos relacionados às diferentes crenças religio- sas}

No sistema cultural, a religião fornece respostas e sentido à vida para quem procura. Muitas religiões, ao pregarem o pós-vida como salvação ou como novo mundo, fornecem também um amparo, auxiliando na construção e prática da fé. A religião evangélica, por exemplo, tem nítida a vinculação entre a vida presente e a vida celestial ${ }^{37,38}$

A religião faz parte da vida de $92 \%$ da população brasileira, segundo censo IBGE de 2010 (publicado em $2012)^{39}$, sendo esta dividida em $64,6 \%$ de católicos, $22,2 \%$ de evangélicos, $2,0 \%$ de espíritas e $0,3 \%$ de religiões afrodescendentes. As demais religiões, os ateus e os agnósticos representam o restante da população brasileira (IBGE, 2012) (39 $^{39}$

A religiosidade permite à pessoa compreender os significados dos eventos como parte de um propósito ou projeto mais amplo, mediante a crença de que nada ocorre por acaso, e de que acontecimentos da vida são determinados por uma força superior. As religiões não evitam confrontos com a realidade, mas procuram dar sentido ao que acontece. Possibilitam, ainda, a crença de que tais eventos podem levar ao crescimento pessoal com sabedoria, equilíbrio e maturidade ${ }^{37,40-42}$.

Boa parte dos autores, dentre eles Lukoff (1992) (3) e Worthington et al. (1996) ${ }^{43}$, definem a religiosidade como a adesão individual a crenças e concepções religiosas específicas, ligadas a uma instituição ou doutrina (religião). A crença em um sentido que ultrapassa as situações concretas da existência, em uma força superior, lei maior ou energia suprema ganharia a denominação de espiritualidade ${ }^{41,42}$.

\footnotetext{
(2) Freud S. O mal-estar na civilização. In: Freud S. Edição standard brasileira das obras psicológicas completas de Sigmund Freud Vol. 21. Rio de Janeiro: Imago; 1976. p. 81-171 apud 34

(3) Lukoff D. Toward a more culturally sensitive DSM-IV. (Psychoreligious and psychospiritual problems). The Journal of nervous and mental disease 1992;180:673-82 apud 39.
} 
Albert Einstein dizia que "a ciência sem religião é paralítica; a religião sem a ciência é cega" "44. O cientista Francis Collins, que estudou o genoma humano disse ser a ciência o único caminho para entender a natureza, sendo que se bem utilizada permite conhecer muitos detalhes da existência material. Porém a ciência ainda não foi capaz de responder algumas perguntas como o que acontece após a morte, qual o objetivo da existência terrena. Nesse espaço, a religião traz uma satisfação ao ser humano, ao dar uma explicação aceitável aos fenômenos que a ciência não explica. Ambas trabalham juntas para gerar conhecimento e tranquilidade entre os seres humanos. ${ }^{44}$

E visando entender a visão das religiões sobre a ortotanásia, procuramos entender antes, também, a visão das religiões sobre o morrer e o que acontece após a morte. A crença em uma nova vida, ou em uma salvação após a morte, pode ser um fator de alívio ao paciente terminal, excluindo o medo do depois, e permitindo dedicar-se somente aos problemas atuais, familiares, sociais e fisiológicos. Porém, muitas religiões consideram a morte uma fase de julgamento, do juízo final, o que pode ocasionar o medo do morrer.

Os ateus acreditam que não exista nenhuma vida após a morte. O homem morre e acaba. Eles fundamentam sua crença no fato de não haver comprovações da vida após a morte, ou de reencarnação ou de alguém ressuscitado. Quando morto, o homem vira pó e então, não há nada, além disso: "Es pó e ao pó voltarás ${ }^{(4)) " 45}$.

\section{Budismo}

Sidarta Gautama, Buda, é o centro desta doutrina, não considerada exatamente como religião. Ele é considerado um guia espiritual. Buda foi quem conseguiu libertar-se do ciclo da morte e reencarnação quando atingiu a iluminação, o paranirvana ${ }^{46}$.

O budismo considera importante a consciência da impermanência e da morte. Como a morte é certa, devemos nos preparar para ela. O seguidor do Budismo precisa dedicar sua vida à realização de seu Dharma e nunca adiá-lo, visando paz e felicidade eterna. Acreditase que dessa vida nada se leva, devendo se libertar do material. Também os sentimentos ruins não devem ser cultivados, como remorsos, arrependimentos, pois isto alterará o renascimento posterior, influenciará no carma. É do paciente a decisão quanto ao tempo e à forma de morrer, sob a pena de violação aos princípios budistas ${ }^{45-47}$.

Os budistas aceitam que o paciente rejeite alimentos e cuidados médicos que não ocasionarão melhora do estado clínico, não havendo melhora da qualidade de vida, mas somente postergando o morrer. E, mais importante do que viver mais dias, é viver com qualidade os dias até a morte ${ }^{45}$.

\section{Catolicismo}

São dois bilhões de seguidores atualmente no mundo que acreditam que a morte é uma transição para a ressurreição, e o destino após a morte pode ser o céu ou o inferno, dependendo das condutas em vida ${ }^{46,48}$.

É a religião mais difundida no mundo, com diversos documentos mostrando a posição contrária à eutanásia e à distanásia. No que tange à eutanásia, a Declaração sobre a Eutanásia, de 1980, da Sagrada Congregação para a Doutrina da Fé, conceitua a mesma como uma violação da Lei divina, uma ofensa à dignidade humana, um crime contra a vida e um atentado contra a humanidade ${ }^{3}$.

Em relação à distanásia, o arcebispo Dom Raymundo Damasceno Assis, presidente da Conferência Nacional dos Bispos do Brasil (CNBB), referiu que "A morte não é uma doença para a qual devamos achar cura. É necessário que o homem reconheça e aceite a própria realidade e os próprios limites". O papa João Paulo II, na Encíclica Evangelium Vitae (1995), relatou: “Quando a morte se anuncia iminente e inevitável, pode-se em consciência renunciar à vida, sem, contudo, interromper os cuidados normais devidos ao doente em casos semelhantes (...). A renúncia a meios extraordinários ou desproporcionais não equivale aos suicídios ou à eutanásia; exprime, antes, a aceitação da condição humana diante da morte" .

O papa Bento XVI, no dia Mundial do Enfermo de 2007, afirmou ser necessário criar condições para os pacientes poderem suportar as doenças incuráveis e enfrentar a morte com dignidade. Enfatizou também a necessidade de centros de cuidados paliativos, com ajuda humana, acompanhamento espiritual, valorizando o ser humano como um todo, e não como uma doença isolada ${ }^{3}$. "Temos de viver com sabedoria a nossa dimensão de seres mortais e finitos. Para nós, cristãos, estamos nos preparando para a Páscoa definitiva, a passagem desta vida para a vida de plenitude, junto a Deus"48.

Dom Odilo Pedro Scherer, Secretário-Geral da CNBB, refere que a Igreja já aceita a ortotanásia desde 1950: "Quando a morte já se anuncia como inevitável, a decisão de renunciar a possíveis excessos terapêuticos que somente dariam um prolongamento precário e penoso pode ser considerada legítima"3,49,50.

Outros documentos demonstram a aprovação da ortotanásia pela igreja católica. Num discurso do papa Pio XII, em 1958, no qual o mesmo coloca a obrigação de conservar a vida e a saúde, porém não através de meios extraordinários, que imponham carga extraordinária para o paciente e os demais, é dito que devem ser utilizados todos os meios disponíveis, de acordo com o local e a época em que o paciente está doente. Para o pontífice, "se parece que a tentativa de reanimação constitui para a

\footnotetext{
(4) Genesis. In: A Bíblia Sagrada, Editora Geográfica. Capitulo 3, versículo 19.
} 
família uma carga que em consciência não se lhe possa impor, ela pode licitamente insistir para que o médico interrompa suas tentativas, e este último pode licitamente ceder a isto" $"$.

$\mathrm{Na}$ declaração, de 5 de maio de 1980, da Congregação para a Doutrina da Fé(5), é referido: “É lícito interromper a aplicação de meios desproporcionais quando os resultados não correspondem aos esforços aplicados" - e a legitimidade de deixar morrer em paz: "É lícito contentar-se com os meios normais que a Medicina pode oferecer" 51 .

O papa João Paulo II, na Constituição Apostólica Fidei depositum, de 11 de outubro de 1992, considerou legítima a interrupção de procedimentos médicos onerosos, perigosos, extraordinários, com resultados fora do esperado. Concorda, desta forma, não em provocar a morte, mas sim em não impedi-la ${ }^{49,51}$.

\section{Cultos afrodescendentes}

Neste grupo entram a umbanda e o candomblé, as religiões mais conhecidas entre os cultos afrodescendentes. Mas também se pode inferir que os conceitos apresentados para estes dois cultos sejam semelhantes ao pregado por outros cultos religiosos afrodescendentes. Os cultos afrodescendentes acreditam numa Lei Maior que regeria os mistérios da vida e da morte. O candomblé considera que morrer seria passar a outra dimensão, permanecendo com outros espíritos, orixás e guias ${ }^{52}$

A Umbanda, por sua criação com diversas influências, sofreu variações de doutrinas e de crenças. Desta forma, parte dos umbandistas creem na divisão entre céu e inferno, e outra parte em reencarnação e carma. No entanto, ambas têm em comum a crença na influência das ações em vida no que ocorrerá após a morte. A morte seria apenas uma parte do ciclo evolutivo, e a reencarnação, a base da evolução. Após a morte o espírito carrega consigo alegrias, mágoas, dores e crenças, e deve adaptar-se à nova realidade espiritual ${ }^{52}$.

Pouco se encontra na literatura sobre a posição dos cultos afrodescendentes em relação à ortotanásia, talvez pelo fato de muitos cultos afrodescendentes apresentarem como costume a transmissão oral dos conhecimentos. No entanto, os dados remetem à valorização da opinião do doente, à sua autonomia e, com uma visão religiosa de evolução, de crescimento, com o processo de morte e reencarnação. Não foi percebida opinião contraria à ortotanásia, mas reforça-se o peso cármico da eutanásia.

\section{Espiritismo - Kardecistas (Allan Kardec)}

Os espíritas acreditam que a vida do corpo é apenas uma transição, passageira, devido ao esgotamento dos órgãos. Após a morte do corpom, a alma volta à vida eterna, sem sofrimento ao corpo. Após a morte, de acordo com a afeição, seria possível encontrar amigos e parentes. $\mathrm{O}$ espírito pode voltar à existência corporal diversas vezes através da reencarnação, para purificar a $\operatorname{alma}^{53}$.

O espiritismo é favorável à morte natural, a que ocorre no tempo certo. No respeito à autonomia, às crenças, medos, e visando a atender os desejos do paciente, devem ser ofertadas medidas de conforto físico e espiritual, possibilitando morrer sem dor e viver com dignidade os últimos dias de vida terrena. Durante o processo de morrer há o aperfeiçoamento do espírito do doente e do médico envolvido com o paciente, principalmente se ambos acreditam na realidade da vida imortal $^{53}$.

\section{Hinduísmo}

O Hinduísmo acredita que a alma reencarnaria diversas vezes e após reencarnação a alma passaria para outra pessoa ou animal. A alma seguiria um ciclo, denominado de Roda de Samsara, com o objetivo de evoluir sem precisar reencarnar novamente. Ao chegar a esse ponto a pessoa atinge a iluminação (Moksha) $)^{46,54,55}$.

Para chegar ao Moksha existem vários caminhos, entre eles: Jnana Marga (caminho da sabedoria), Karma Marga (caminho da ação) e Bhakti Marga (caminho da devoção). Cada caminho requer uma anulação do eu, dos sentidos e de outros aspectos terrenos ${ }^{51}$.

Consideram que a boa morte é a que ocorre no tempo astrológico certo, na pessoa idosa. A morte repentina é considerada ruim. Porém não valorizam a vida mantida artificialmente. Há Karma negativo para médico e paciente em caso de eutanásia ${ }^{51}$.

\section{Islamismo}

Islam é uma palavra de origem árabe que significa submissão, a submissão dos muçulmanos perante a vontade de Deus (Allah).

Morrer significa separar-se da vida. Seria o ingresso para a vida eterna em outro mundo. Eliminaria a vida terrena em favor da eternidade. Porém, a pessoa só morreria com autorização de Deus. "Deus dá a vida, e Ele faz morrer. Uma pessoa morre quando está escrito" 56 .

A pessoa, ao morrer, ficaria aguardando o dia da ressurreição. Alá trará a vida aos mortos no último dia de vida, dia da ressurreição (Ya Umul Haxr). Eles serão julgados e encaminhados ao Céu ou ao Inferno. O objetivo de alcançar o Paraíso após a morte define a forma de agir na Terra ${ }^{46,51 \text {, }}$

\footnotetext{
${ }^{(5)}$ Seper FC, Hamer J. Declaração sobre a eutanásia - Sagrada Congregação para a doutrina da Fé. apud 51.
} 
Após a morte, vivem-se duas fases: a primeira (Alamul Barzakh) vai desde a morte até a ressurreição; e a segunda (Alamul Mahshar) vai da ressurreição até o destino final eterno.

O Islamismo tem no código islâmico de ética médica um importante documento elaborado pela Organização Islâmica de Ciências Médicas e aprovado na $1^{\text {a }}$ Conferência Internacional de Medicina Islâmica, realizada no Kuwait em 1981. O médico islâmico deve saber que a vida é de Deus, dada somente por ELE e que a morte é conclusão de uma vida e início de outra. Sua função é proteger a vida humana. "A morte é uma verdade sólida (...) e é o fim de tudo, exceto de Deus". O médico é somente um instrumento de Deus, para aliviar os sintomas e as doenças do povo ${ }^{31,57}$.

O islamismo diz que, nos casos em que a vida não pode ser restaurada, deve-se evitar manter o paciente em estado vegetativo utilizando medidas heroicas. O médico deve manter a vida e não prolongar o processo do morrer. Nos pacientes terminais, o médico cuidará do paciente, com atenção, apoio moral e alivio da dor e aflição $0^{44,56}$.

Pode-se inferir que a ortotanásia poderia ser admitida pela religião islâmica. Segue esta assertiva Maria de Fátima Freire de Sá, ao ponderar que "[...] torna-se imperioso concluir que o islamismo condena o suicídio e a eutanásia ativa. Contudo, traz certa simpatia em relação à ortotanásia, uma vez que condena a adoção de medidas heroicas para manter, a todo custo, a vida de alguém com morte iminente" 32 .

\section{Judaísmo}

São descendentes do patriarca Abraão, e para eles, o Messias ainda virá. Os judeus acreditam em vida após a morte e em céu e inferno. Acreditam na reencarnação como forma de evolução ${ }^{46}$.

Os judeus entendem que a passagem pela terra é temporária. Acreditam que no final os mortos ressuscitarão e se juntarão em Israel para viver eternamente.

Pela lei judaica, o médico tem mais influência sobre o tratamento que a autonomia do paciente. A lei judaica entende que se não há cura e não há nada mais a fazer, não devemos prolongar o processo de morrer ${ }^{58}$.

A questão de quando precisamente termina a vida humana é muito discutida entre os bioeticistas judeus contemporâneos. Quando a cura não pode ser conseguida, o cuidado é sempre exigido até o final da vida humana. Podem ser suspensas medidas de prolongamento da vida, e o tratamento não analgésico. Na Torá, livro sagrado dos judeus, está escrito: "Todo aquele cuja existência tornouse miserável está autorizado a abster-se de fazer algo para prolongá-la"(6). A oração para a morte do paciente é permitida em casos de agonia extrema e quando não existe mais esperança real de recuperação ${ }^{44}$.

Na religião, é expressa a proibição do homicídio, porém admite-se interromper suportes vitais que configurem impedimentos à morte do doente terminal. Há um encorajamento para o doente encarar a morte, sendo ele sempre assistido, encorajado, consolado ${ }^{32,51}$.

\section{CONCLUSÕES}

Eticamente e legalmente a ortotanásia é admitida como conduta a ser adotada diante de pessoas em processo de morte, quando todas as possibilidades terapêuticas foram esgotadas, não havendo, assim, possiblidade de reversão da condição clínica fatal. Independentemente da crença religiosa, a dignidade humana diante do fim inevitável é fator preponderante nas condutas médicas. $\mathrm{O}$ alívio do sofrimento através de cuidados paliativos não deve ser entendido como desrespeito à religiosidade ou à condição humana, mas uma forma de abrandar a transição entre a vida material e a morte. Mas um dado que nunca deve ser desconsiderado é relativo à obrigação do médico em procurar conhecer e compreender a opinião dos pacientes e dos familiares quanto às crenças religiosas.

Algumas religiões não foram incluídas neste estudo devido às suas diversas ramificações e à carência de dados na literatura disponível. Outros estudos poderão suprir esta lacuna, eventualmente entrevistando líderes religiosos e mostrando a visão de diversas religiões, de forma mais ampla.

Xavier MS; Miziara CSMG; Miziara ID. End of life: ethical and religious issues about orthotanasia. Saúde, Ética \& Justiça. 2014;19(1);26-34.

ABSTRACT: Orthothanasia has been widely discussed in recent years, especially after the publication of CFM Resolution No. 1805/2006, and later with the publication of the new Code of Medical Ethics. The aim of this study is to identify and address the ethical and religious issues pertaining to the subject, and that should be considered regarding patients in the terminal stages of life. A literature review was conducted from major databases of open access and published texts. Most religions accepts orthothanasia as a natural process, like the death. We conclude that religion does not interfere negatively in relation to orthothanasia.

KEYWORDS: Hospice Care; Palliative Care; Religion.

\footnotetext{
(6) Chaves A. Direito à vida e ao próprio corpo. São Paulo, Revista dos Tribunais, 1994 apud 6.
} 


\section{REFERÊNCIAS}

1. Fraga F, Boas RFOV, Mendonça ARA. Significado, para os médicos, da terminalidade da vida e dos cuidados paliativos. Rev Bioét (Impr). 2012; 20(3):514-9.

2. Saraiva AMP. Suspensão de tratamento em unidades de terapia intensiva e seus fundamentos éticos. Rev Bioét (Impr). 2012; 20(1):150-63.

3. Pazin-Filho A. Morte: considerações para a prática médica. Medicina (Ribeirão Preto). 2005; 38(1):20-5.

4. Kovács MJ. Educação para a Morte. Psicol Clín Profis. 2005; 25(3):484-97.

5. Kovács MJ. Morte e desenvolvimento humano. $5^{\mathrm{a}}$ ed. São Paulo: Casa do psicólogo; 2013. p.195-211.

6. Bomtempo TV. Análise constitucional da ortotanásia: o direito de morrer com dignidade. Revista Âmbito Jurídico. [Internet]. 2011. [acesso em 2013 set 20]. Disponível em: http://www.ambitojuridico.com.br/site/?n link=revista artigos_leitura\&artigo_id $=10386 \&$ revista_caderno $=6$

7. Lima PMS. Aspectos éticos e legais da aplicabilidade da ortotanásia. Jus Societas. 2008; 2(1):1-20.

8. Clotet J. O respeito à autonomia e aos direitos dos pacientes. Revista da AMRIGS, Porto Alegre. 2009; 53(4):432-5.

9. Bomtempo TV. Diretivas antecipadas: instrumento que assegura a vontade de morrer dignamente. Revista Ambito Jurídico. [Internet]. 2012. Disponível em: http://www. ambito-juridico.com.br/site/index.php?n_link=revista artigos_leitura\&artigo_id $=11206$

10. Rocha AR, Buonicore GP, Silva AC, Pithan LH, Feijó AGS. Declaração prévia de vontade do paciente terminal: reflexão bioética. Rev Bioét (Impr). 2013; 21(1):84-95.

11. Garcia IA. Aspectos médicos e jurídicos da eutanásia. Revista Brasileira de Ciências Criminais. 2007; 15(67):25375.

12. Batista KT, Seidl EMF. Estudo acerca de decisões éticas na terminalidade da vida em unidade de terapia intensiva. Com. Ciências Saúde. 2011; 22(1):51-60.

13. Costa WJ, Felix A. Ortotanásia sob a luz dos direitos humanos. [Artigo - trabalho de conclusão de curso]. Várzea Grande: UNIVAG - Centro Universitário; 2011.

14. Sztajn R. Terminalidade da vida: a ortotanásia e a constitucionalidade da res. CFM 1.805/2006. Revista de Direito Constitucional e Internacional. 2009; 17(66):24557.

15. Emanuel EJ. The ends of human life. Cambridge, USA: Harvard University Press; 1994. p.42-96.

16. Almeida LD, Machado MC. Atitude médica e autonomia do doente vulnerável. Revista Bioética. 2010; 18(1):16583.

17. Feio AGO, Oliveira CC. Responsabilidade e tecnologia: a questão da distanásia. Rev Bioét (Impr). 2011; 19(3):61530.

18. Villas-Bôas ME. A ortotanásia e o direito penal brasileiro. Revista Bioética. 2008; 16(1):61-83.

19. Santos OM. Sofrimento e dor em cuidados paliativos: reflexões éticas. Rev Bioét (Impr). 2011; 19(3):683-95.

20. Corrêa AL, Silva PR, Meglhioratti FA, Caldeira AMA. Aspectos históricos e filosóficos do conceito de vida: contribuições para o ensino de biologia. Filosofia e história da biologia. 2008; 3:21-40.
21. Lima C. Do conceito ao diagnóstico de morte: controvérsias e dilemas éticos. Medicina Interna - Revista da sociedade portuguesa de medicina interna. 2005; 12(1):6-10.

22. Brasil. Conselho Federal de Medicina. Resolução CFM $\mathrm{n}^{\mathbf{0}} 1480 / 97$, de 08 de agosto de 1997. [Internet]. Diário Oficial da União. 1997 ago 21. [acesso em 2013set 18]. Disponível em: http://www.portalmedico.org.br/ resolucoes/CFM/1997/1480_1997.htm

23. BVS - Biblioteca Virtual em Saúde (Ministério da Saúde). Morte encefálica [Internet]. Brasília; 2008. [acesso em 2013 set 20]. Disponível em: http://bvsms.saude.gov.br/ bvs/dicas/146morte encefalica.html

24. Capello EMCS, Velosa MVM, Salotti SRA, Guimarães HCQCPG. Enfrentamento do paciente oncológico e do familiar/cuidador frente à terminalidade de vida. J Health Sci Inst. 2012; 30(3):235-40.

25. Andrade EO. A Ortotanásia e o Direito Brasileiro - A Resolução CFM n. 1.805/2006 e algumas considerações preliminares à luz do Biodireito Brasileiro. Bioethikos. 2011; 5(1):28-34.

26. Nunes R. Proposta sobre suspensão e abstenção de tratamento em doentes terminais. Revista Bioética. 2009; 17(1):29-39.

27. Junges JR, Cremonese C, Oliveira EA, Souza LL, Backes V. Reflexões legais e éticas sobre o final da vida: uma discussão sobre a ortotanásia. Revista Bioética. 2010; $18(2): 275-88$.

28. Pinto, JRC. Questões actuais de ética médica. $3^{\mathrm{a}}$ ed. Braga: Editorial AO; 1990

29. Brito AJSL, Rijo JMSL. Estudo jurídico da eutanásia em Portugal: direito sobre a vida ou dever de viver. Coimbra; Almedina; 2000.

30. Pessini L. Lidando com pedidos de eutanásia: a inserção do filtro paliativo. Revista Bioética. 2010; 18(3):549-60.

31. Brasil. Conselho Federal de Medicina. Código de Processo Ético Médico. Resolução CFM n ${ }^{\circ} 1.805 / 2006$, de 28 de novembro de 2006. Dispõe sobre a ortotanásia. [acesso em 2014 jan 08]. Disponível em: http://www.portalmedico.org. br/resolucoes/CFM/2006/1805_2006.htm

32. Brasil. Conselho Federal de Medicina. Código de Ética Médica. Resolução CFM n ${ }^{\circ} 1.931 / 2009$, de 24 de setembro de 2009. Dispõe sobre o Código de ética Médica. [acesso em 2014 jan 05]. Disponível em: http://www.portalmedico. org.br/resolucoes/CFM/2009/1931_2009.pdf

33. Brasil. Constituição da Republica Federativa do Brasil de 1988. Título II: Dos Direitos e Garantias Fundamentais. Capítulo I: Dos Direitos e Deveres Individuais e Coletivos. Artigo $5^{\circ}$. [acesso em 2014 jan 08]. Disponível em: http:// www.planalto.gov.br/ccivil_03/constituicao/constituicao. htm

34. Maciel KDSA, Rocha ZJB. Freud e a Religião: Possibilidades de Novas Leituras e Construções Teóricas. Psicol Ciênc Prof. 2008; 28(4):742-53. DOI: http://dx.doi. org/10.1590/S1414-98932008000400007

35. Hinshaw DB. Spiritual issues in surgical palliative care. Surg Clin North Am. 2005; 85(2):257-72. DOI: http:// dx.doi.org/10.1016/j.suc.2004.11.002

36. Saporetti LA. Espiritualidade em cuidados paliativos. In: Oliveira RA (coord.). Cuidados paliativos. São Paulo: 
Xavier MS; Miziara CSMG; Miziara ID. Terminalidade da vida: questões éticas e religiosas sobre a ortotanásia.

Conselho Regional de Medicina do Estado de São Paulo; 2008. p.521-31.

37. Rutty JE. Religious Attitudes to death. In: Payne-James J, Byard R, Corey T, Henderson (editors). Encyclopedia of Forensic and Legal Medicine - Vol. 3. Waltham, USA: Elsevier Academic Press; 2005. p.525-34.

38. Mitchell D. Spiritual and cultural issues at the end of life. Medicine. 2007; 36(2):109-10. DOI: http://dx.doi. org/10.1016/j.mpmed.2007.11.011

39. Instituto Brasileiro de Geografia e Estatística - IBGE. Censo Demográfico 2010, Características gerais da população, religião e pessoas com deficiência. Rio de Janeiro: IBGE; 2012.

40. Fletcher SK. Religion and life meaning: Differentiating between religious beliefs and religious community in constructing life meaning. J Aging Stud. 2004; 18(2):17185. DOI: http://dx.doi.org/10.1016/j.jaging.2004.01.005

41. Barbosa KA, Freitas MH. Religiosidade e atitude diante da morte em idosos sob os cuidados paliativos. Rev Kairós. 2009; 12(1):113-34

42. Bousso RS, Serafim TS, Misko MD. Histórias de vida de familiares de crianças com doenças graves: relação entre religião, doença e morte. Rev Latinoam Enferm. 2010; 18(2):[07 telas]. DOI: http://dx.doi.org/10.1590/S010411692010000200003

43. Worthington Jr. EL, Kurusu TA, McCullough ME, Sandage SJ. Empirical research on religion and psychotherapeutic processes and outcomes: A 10-year review and research prospectus. Psychol Bull. 1996; 119(3):448-87.

44. Conselho Federal de Medicina - CFM. Entrevista ao CFM: CNBB apoia ortotanásia [Internet]. Brasília, DF; 2012. [2012 set 24; acesso em 2013 set 18] Disponível em: http://portal.cfm.org.br/index.php?option=com_content \&view $=$ article \&id=23257:entrevista-ao-cfm-cnbb-apoiaortotanásia\&catid $=3$

45. Silva CPB, Vaz TBC. A morte segundo a visão de diferentes religiões. [Mini-Monografia] [Internet]. Niterói, RJ: Faculdade de História - Universidade Federal Fluminense; 2002. [acesso em 2013 ago 20]. Disponível em: http:// www.trabalhosfeitos.com/ensaios/Socio/38657626.html

46. Pessini L. A eutanásia na visão das maiores religiões (budismo, islamismo, judaísmo e cristianismo). In: Barchifontaine CP, Pessini L (orgs.). Bioética: alguns desafios. $2^{\mathrm{a}}$ ed. São Paulo: Edições Loyola; 2002. p.261-82.
47. Keown D. End-of-life: the buddhist view. Lancet. 2005; 366(9489):952-5. DOI: http://dx.doi.org/10.1016/S01406736(05)67323-0

48. Engelhardt Jr HT, IItis AS. End-of-life: the traditional Christian view. Lancet. 2005; 366(9490):1045-9. DOI: http://dx.doi.org/10.1016/S0140-6736(05)67383-7

49. Puchalski CM, O'Donell E. Religious and spiritual beliefs in end of life care: how major religions view death and dying. Tech Reg Anesth Pain Manag. 2005; 9(3):114-21. DOI: http://dx.doi.org/10.1053/j.trap.2005.06.003

50. Markwell H. End-of-life: a catholic view. Lancet. 2005; 366(9491):1132-5. DOI: http://dx.doi.org/10.1016/S01406736(05)67425-9

51. Agência Senado. Camata cita manifestações das diferentes religiões sobre a ortotanásia [Internet]. Brasília, DF; 2009 [2009 set 17; acesso em 2013 set 12]. Disponível em: http://www12.senado.gov.br/noticias/materias/2009/09/17/ camata-cita-manifestacoes-das-diferentes-religioes-sobrea-ortotanasia

52. Nascimento C. Saiba como a morte é vista em diferentes religiões e doutrinas [Internet]. Revista Época. 2004 ago 05. [acesso em 2013 set 18]. Disponível em: http://revistaepoca. globo.com/Revista/Epoca/0,EDG65777-5856,00.html

53. Santos JRP, Nobre M. Ortotanásia - pronunciamento da AME-Brasil [Internet]. Revista Internacional de Espiritismo. 2007 mai. [acesso em 2013 set 18]. Disponível em: http://www.oclarim.org/site/

54. Miranda S. Como as grandes religiões encaram o momento da morte [Internet]. Mundo Estranho. [acesso em 2013 set 17]. Disponível em: http://mundoestranho.abril.com.br/ materia/como-as-grandes-religioes-encaram-o-momentoda-morte

55. Firth S. End-of-life: a Hindu view. Lancet. 2005; 366(9486):682-6. DOI: http://dx.doi.org/10.1016/S01406736(05)67141-3

56. Sachedina A. End-of-life: the Islamic View. Lancet. 2005; 366(9487):774-9. DOI: http://dx.doi.org/10.1016/S01406736(05)67183-8

57. IslamReligion.com. Crença na vida após a morte [Internet]. 2009. [2009 jan 07; acesso em 2013 ago 27]. Disponível em: http://www.islamreligion.com/pt/articles/38/

58. Dorff EM. End-of-life: Jewish perspectives. Lancet. 2005; 366(9488):862-5. DOI: http://dx.doi.org/10.1016/S01406736(05)67219-4 